\footnotetext{
${ }^{1}$ Department of Atmospheric Sciences, National Taiwan University, Taipei, Taiwan
}

${ }^{2}$ Department of Earth Sciences, National Taiwan Normal University, Taipei, Taiwan

\title{
Observed and projected climate change in Taiwan
}

\author{
H.-H. Hsu ${ }^{1}$ and C.-T. Chen ${ }^{2}$
}

With 11 Figures

Received February 5, 2001

Revised July 30, 2001

\section{Summary}

This study examined the secular climate change characteristics in Taiwan over the past 100 years and the relationship with the global climate change. Estimates for the likelihood of future climate changes in Taiwan were made based on the projection from the IPCC climate models.

In the past 100 years, Taiwan experienced an island-wide warming trend $\left(1.0-1.4{ }^{\circ} \mathrm{C} / 100\right.$ years). Both the annual and daily temperature ranges have also increased. The warming in Taiwan is closely connected to a large-scale circulation and SAT fluctuations, such as the "cool ocean warm land" phenomenon. The water vapor pressure has increased significantly and could have resulted in a larger temperature increase in summer. The probability for the occurrence of high temperatures has increased and the result suggests that both the mean and variance in the SAT in Taiwan have changed significantly since the beginning of the 20th century. Although, as a whole, the precipitation in Taiwan has shown a tendency to increase in northern Taiwan and to decrease in southern Taiwan in the past 100 years, it exhibits a more complicated spatial pattern. The changes occur mainly in either the dry or rainy season and result in an enhanced seasonal cycle. The changes in temperature and precipitation are consistent with the weakening of the East Asian monsoon.

Under consideration of both the warming effect from greenhouse gases and the cooling effect from aerosols, all projections from climate models indicated a warmer climate near Taiwan in the future. The projected increase in the area-mean temperature near Taiwan ranged from $0.9-2.7^{\circ} \mathrm{C}$ relative to the $1961-1990$ averaged temperature, when the $\mathrm{CO}_{2}$ concentration increased to 1.9 times the 1961-1990 level. These simulated temperature increases were statistically significant and can be attributed to the radiative forcing associated with the increased concentration of greenhouse gases and aerosols. The projected changes in precipitation were within the range of natural variability for all five models. There is no evidence supporting the possibility of precipitation changes near Taiwan based on the simulations from five IPCC climate models.

\section{Introduction}

The climate of the earth has been experiencing unprecedented global warming since the end of the little ice age. While the global averaged surface air temperature (hereafter referred to as SAT) has increased by between about 0.3 and $0.6^{\circ} \mathrm{C}$ since the late 19th century (IPCC, 1996), regional temperatures (and climate) might experience very different changes (Jones et al., 1999). Overall, the land surface temperature (hereafter referred to as LST) has increased at a rate faster than the sea surface temperature (hereafter referred to as SST; IPCC, 1996). It was also found that while the LST in the extratropical Northern Hemisphere increased in the past 100 years, the SST was actually dropped, e.g., the so called "cool ocean warm land" (COWL) documented by Wallace et al. (1996). A recent analysis by Hansen et al. (1999) revealed a more complicated spatial structure embedded in the global warming signals. For example, southeastern North America experienced a cooling trend from 1950 to 1998, while northwestern 


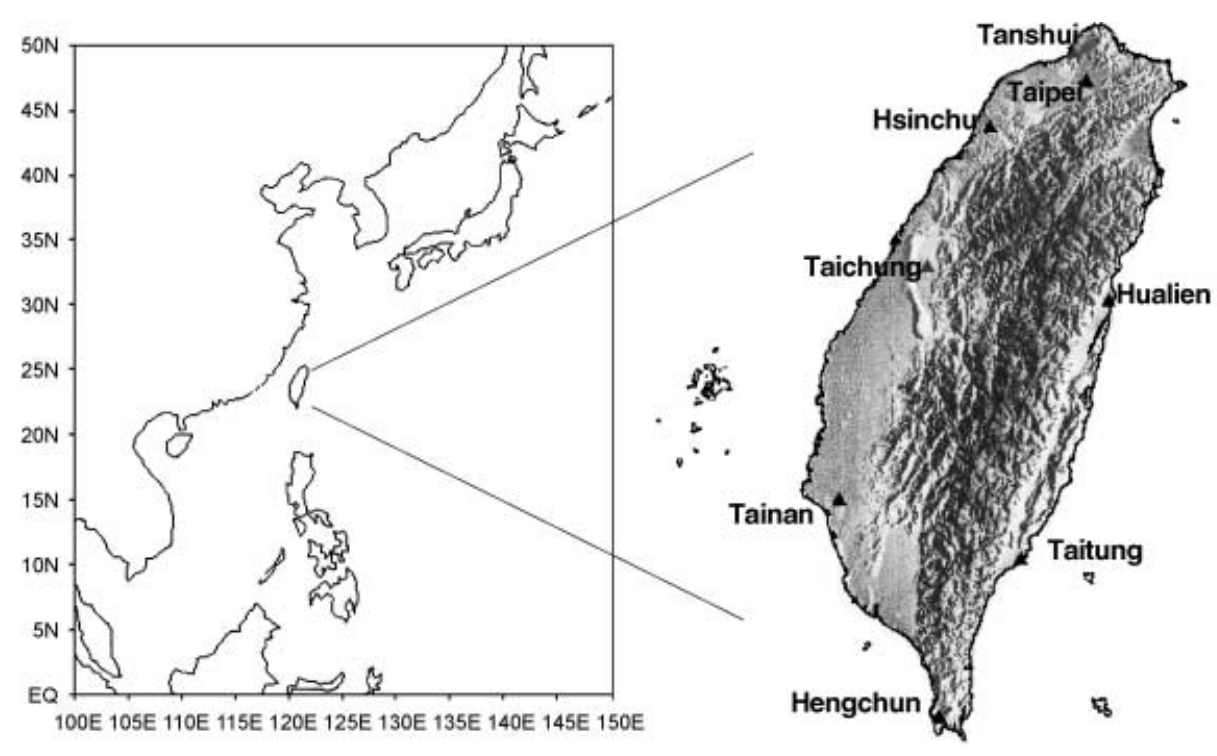

Fig. 1. Geographical location of Taiwan and the major meteorological stations
North America experienced a significant warming trend. This geographical difference is also evident in the Tropical Pacific. For example, warming trends were identified in the Western Pacific while cooling trends were found in the Eastern Pacific (Cane et al., 1997). This contrast indicates a strengthened SST gradient in the Equatorial Pacific.

It is difficult at this stage to differentiate the relative contribution of the natural variation and the anthropogenic greenhouse effect to this warming. While the concentration of greenhouse gases and aerosols continues to rise, what will occur with this warming trend in the future is an even more difficult question to answer. To project the potential impact of future climate change, it is necessary to understand the past climate change on a regional scale. This information can be used not only to explore the responsible mechanism but also to evaluate the performance of the climate model. Although the present climate models used to project future climate change are often too coarse to accurately resolve regional climate changes, it is important to understand the limitations of these climate models. After all, they are the only tools that are presently available to be used for future projections.

Regional climate change can be a part of the global climate change pattern but can also be influenced significantly by regional effects. In this study, we examined the climate changes occurring in Taiwan, which is a highly populated island country located off the eastern coast of China (Fig. 1). Taiwan's climate variations are predominantly affected by the East Asian monsoon and further complicated by the mountainous terrain and land-sea distribution. The objectives of this study are two-fold. First, Taiwan's climate change characteristics over the past 100 years and its climate change relationship with the global climate changes were examined. Second, the likelihood of future climate changes in Taiwan was projected based on global climate model projections.

\section{Data and analysis procedure}

The data analyzed in this study included (a) the SAT, precipitation, and humidity at Taiwan's major meteorological stations that have the longest records in Taiwan, (b) the Blended SST and LST anomaly (hereafter referred to as LSST), (c) the Global Mean Sea-Level Pressure (GMSLP). The earliest meteorological records in Taiwan started in 1897 (Tables 1 and 2) at several stations, which are rather uniformly located around the island (Fig. 1). The LSST is the blended data set combining the University of East Anglia Land Surface Temperature Anomalies (Jones, 1994) and the MOHSST6 Sea-Surface Temperature Anomalies (Parker et al., 1995). The resolution is $5^{\circ}$ by $5^{\circ}$ and the length is 1851-1995. The anomalies are defined as the departures from the 1961-1990 climatology. The GMSLP is also on 
Table 1. Trend of mean air temperature ${ }^{\circ} \mathrm{C}\left({ }^{*}-\right.$ statistically significant at the 0.05 level $)$

\begin{tabular}{|c|c|c|c|c|c|c|}
\hline Trend $\quad$ Station & $\begin{array}{l}\text { Taipei } \\
1897 \sim 1999\end{array}$ & $\begin{array}{l}\text { Taichung } \\
1897 \sim 1999\end{array}$ & $\begin{array}{l}\text { Hualien } \\
1911 \sim 1999\end{array}$ & $\begin{array}{l}\text { Tainan } \\
1897 \sim 1999\end{array}$ & $\begin{array}{l}\text { Taitung } \\
1901 \sim 1999\end{array}$ & $\begin{array}{l}\text { Hengchun } \\
1897 \sim 1999\end{array}$ \\
\hline Annual $\left({ }^{\circ} \mathrm{C} / 100 \mathrm{yr}\right)$ & $1.09^{*}$ & $1.00^{*}$ & $1.13^{*}$ & $1.16^{*}$ & $1.09^{*}$ & $0.83^{*}$ \\
\hline Spring $\left({ }^{\circ} \mathrm{C} / 100 \mathrm{yr}\right)$ & $1.28^{*}$ & $1.22^{*}$ & $1.52^{*}$ & $1.55^{*}$ & $1.26^{*}$ & $0.96^{*}$ \\
\hline Summer $\left({ }^{\circ} \mathrm{C} / 100 \mathrm{yr}\right)$ & $1.35^{*}$ & $1.10^{*}$ & $1.59^{*}$ & $1.64^{*}$ & $1.64^{*}$ & $1.05^{*}$ \\
\hline Fall $\left({ }^{\circ} \mathrm{C} / 100 \mathrm{yr}\right)$ & $1.55^{*}$ & $1.39^{*}$ & $1.46^{*}$ & $1.34^{*}$ & $1.39^{*}$ & $1.13^{*}$ \\
\hline Winter $\left({ }^{\circ} \mathrm{C} / 100 \mathrm{yr}\right)$ & $1.16^{*}$ & $1.10^{*}$ & $0.90^{*}$ & $0.94^{*}$ & $0.78^{*}$ & $0.68^{*}$ \\
\hline $\mathrm{T}_{\max }\left({ }^{\circ} \mathrm{C} / 100 \mathrm{yr}\right)$ & $0.92^{*}$ & $0.43^{*}$ & -0.2 & 0.33 & 0.28 & $0.87^{*}$ \\
\hline $\mathrm{T}_{\min }\left({ }^{\circ} \mathrm{C} / 100 \mathrm{yr}\right)$ & $2.12^{*}$ & $1.72^{*}$ & $2.18^{*}$ & $2.21^{*}$ & $1.89^{*}$ & $0.94^{*}$ \\
\hline $\mathrm{T}_{\max } \geq 28^{\circ} \mathrm{C}(\mathrm{day} / \mathrm{yr})$ & 0.071 & $0.213^{*}$ & 0.095 & 0.020 & $0.144^{*}$ & $0.334^{*}$ \\
\hline $\mathrm{T}_{\max } \leq 13^{\circ} \mathrm{C}(\mathrm{day} / \mathrm{yr})$ & $-0.032^{*}$ & -0.011 & 0.004 & -0.001 & 0.001 & - \\
\hline Vapor (hPa/100 yr) & $0.52^{*}$ & -0.56 & -1.33 & $1.45^{*}$ & $0.74^{*}$ & 0.04 \\
\hline
\end{tabular}

Table 2. Trend of precipitation $\left({ }^{*}-\right.$ statistically significant at the 0.05 level)

\begin{tabular}{|c|c|c|c|c|c|c|c|c|}
\hline Trend Station & $\begin{array}{l}\text { Taipei } \\
1897 \sim 1999\end{array}$ & $\begin{array}{l}\text { Tanshui } \\
1901 \sim 1999\end{array}$ & $\begin{array}{l}\text { Hsinchu } \\
1901 \sim 1999\end{array}$ & $\begin{array}{l}\text { Taichung } \\
1897 \sim 1999\end{array}$ & $\begin{array}{l}\text { Hualien } \\
1901 \sim 1999\end{array}$ & $\begin{array}{l}\text { Tainan } \\
1897 \sim 1999\end{array}$ & $\begin{array}{l}\text { Taitung } \\
1901 \sim 1999\end{array}$ & $\begin{array}{l}\text { Hengchun } \\
1897 \sim 1999\end{array}$ \\
\hline Annual (mm/yr) & 1.36 & $3.34^{*}$ & $3.76^{*}$ & -2.63 & $3.43^{*}$ & -1.80 & -0.16 & $-3.99 *$ \\
\hline Spring (mm/yr) & 0.07 & -0.07 & $0.65^{*}$ & -0.04 & -0.11 & 0.03 & -0.15 & -0.07 \\
\hline Summer $(\mathrm{mm} / \mathrm{yr})$ & 0.11 & 0.39 & 0.58 & -0.40 & 0.04 & -0.47 & -0.24 & $-1.21^{*}$ \\
\hline Fall $(\mathrm{mm} / \mathrm{yr})$ & 0.21 & $0.78^{*}$ & 0.29 & -0.18 & $1.14^{*}$ & -0.06 & 0.30 & -0.02 \\
\hline Winter $(\mathrm{mm} / \mathrm{yr})$ & 0.08 & -0.07 & 0.17 & 0.01 & 0.10 & -0.10 & 0.04 & -0.03 \\
\hline Prec. Day (day/yr) & $-0.27^{*}$ & -0.02 & $0.57^{*}$ & $-0.23^{*}$ & -0.16 & $-0.22^{*}$ & $-0.32^{*}$ & $-0.37^{*}$ \\
\hline $\begin{array}{l}\text { Heavy Prec. Day } \\
\text { (day/100 yr) }\end{array}$ & $2.95^{*}$ & $3.80^{*}$ & 2.00 & 0.09 & $2.80^{*}$ & -0.06 & -0.70 & -1.28 \\
\hline
\end{tabular}

a $5^{\circ}$ by $5^{\circ}$ grid and is available from $1871-1994$ (Allan et al., 1996). Linear regression analysis and significant tests at the 0.05 level were applied to the above data to examine whether climatic trends exist.

Climate scenario simulation data from nine climate models were available from the IPCC Data Distribution Center. All nine models were used for three types of simulations, namely the control, the greenhouse gas only, and the greenhouse gas/aerosol. In the control simulation, the concentration of greenhouse gases was fixed at the pre-industrial level and the effect of aerosols was not considered. In the greenhouse gas only and greenhouse gas/aerosol simulations, the concentrations of greenhouse gases and aerosols were programmed to increase with time. The IS92a projection profile (IPCC, 1996) was adopted by most of the models to prescribe the increase in the greenhouse gases and aerosol concentration for the period after 1990. Some models however were forced by the $1 \%$ compound increase in the greenhouse gases concentration. Because of the slightly different increasing trends for the greenhouse gas concentration, it was not necessary for all models to reach the same level of concentration at the same period. The resulting radiative forcings can therefore be very different between the models even in the same period. To minimize the impact of this difference, this study investigated the climate changes in the 19611990 period, defined as $1 \mathrm{CO}_{2}$, and the 30 -year period when the concentration of greenhouse gases reached 1.9 times the present concentration. The changes in temperature and precipitation between 1 and $1.9 \mathrm{CO}_{2}$ were calculated to project the future climate changes. Because of this choice, only five model simulations were long enough in both the greenhouse gas only and the greenhouse gas/aerosol simulations.

These five coupled general circulation models (CGCM) were from (1) the Canadian Center for Climate Modelling and Analysis (CCCma), (2) the Center for Climate Research Studies Japan 
(CCSR), (3) the Australian Commonwealth Scientific and Industrial Research Organization (CSIRO), and (4) the Hadley Centre for Climate Prediction and Research. Two CGCM simulations were produced by the Hadley centre using different versions of the model, i.e., HadCM2 and HadCM3. More information on the specifications for these CGCM can be found on the IPCC Data Distribution Center web page (http://ipcc-ddc.cru.uea.ac.uk/).

The data used for the validation of the presentclimate simulation by the above models were (1) the CRU 1961-1990 mean monthly climatology, (2) The Global Precipitation Climatology Project (GPCP) combined precipitation dataset, (3) the National Centers for Environmental Prediction (NCEP) reanalysis. The CRU data is a data set of mean monthly surface climate over global land areas, excluding Antarctica and is interpolated from station data to the 0.5-degree lat/lon grid (New et al., 1999 and 2000). The spatial resolution of the GPCP data and NCEP reanalysis is $2.5^{\circ}$ by $2.5^{\circ}$. Readers are referred to Huffman et al. (1997), and Kalnay et al. (1996) for the details of the two data sets. Two data sets based on different analysis procedures were used to check the consistency between the "observations". This procedure yields greater confidence in the validation of both simulated temperature and precipitation.

Although this study was designed to investigate the future climate changes in Taiwan, the model resolutions are too coarse to represent climate in Taiwan. This study therefore focused on a larger area covering Taiwan $\left(110^{\circ} \mathrm{E}-130^{\circ} \mathrm{E}\right.$, $\left.15^{\circ} \mathrm{N}-30^{\circ} \mathrm{N}\right)$ and computed area-mean values to project the possible climate changes near Taiwan.

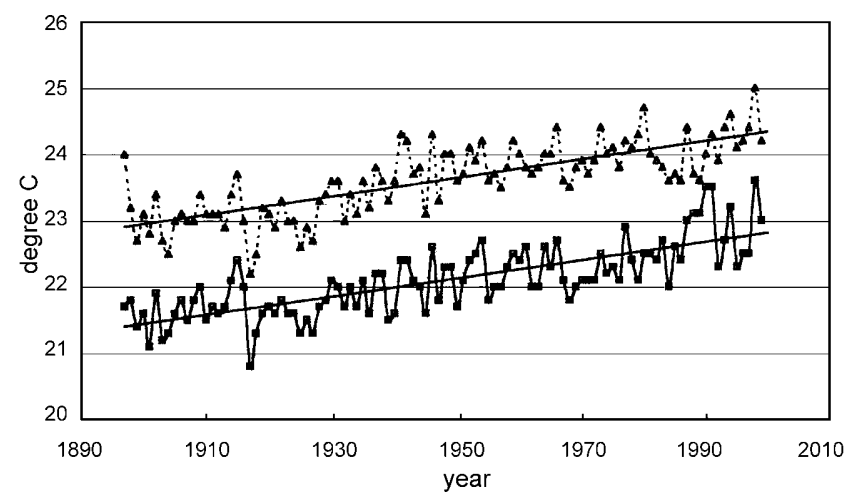

\section{Observed climate change}

\subsection{Surface air temperature}

As shown in Fig. 2 and Table 1 the annual mean SAT at the six major stations in Taiwan exhibit a rising trend since the beginning of the 20th century, in addition to the complicated interannual and interdecadal fluctuations. The warming rates, which are statistically significant at the 0.05 level, range between $1-1.4{ }^{\circ} \mathrm{C} / 100$ years. This homogeneous distribution indicates that Taiwan has been experiencing an island-wide warming since the beginning of the 20th century. This warming trend is consistent with the regional warming trend pattern shown in Fig. 3, which is part of the global COWL pattern documented by previous studies (e.g., Wallace et al., 1997; Jones et al., 1999, and Hansen et al., 1999). The regional pattern, which is accompanied by the warming in North America, the equatorial Eastern Pacific, and the subtropical Indian Ocean (Jones et al., 1999; Hansen et al., 1999), indicates that the largest warming occurred in temperate Asia. The warming region in Asia extends eastward to Japan and southeastward to Taiwan along the coast of China. These rates of increase are in general larger than $1{ }^{\circ} \mathrm{C} / 100$ years and, in the higher latitudes, are larger in the winter than in the summer. The warming observed in Taiwan is apparently associated with and affected by this large-scale warming pattern. An interesting local feature, seen in Fig. 3, is the warming region elongated in the northeast-southwest direction along the east coast of China. This study will show later that this interesting structure can probably be attributed to the climate changes in the East Asian monsoon.
Fig. 2. Annual temperature time series for Taipei (northern Taiwan, solid curve) and Tainan (southern Taiwan, dashed curve). The solid lines are the best-fit linear trends 
annual $(0.05 \mathrm{t})$

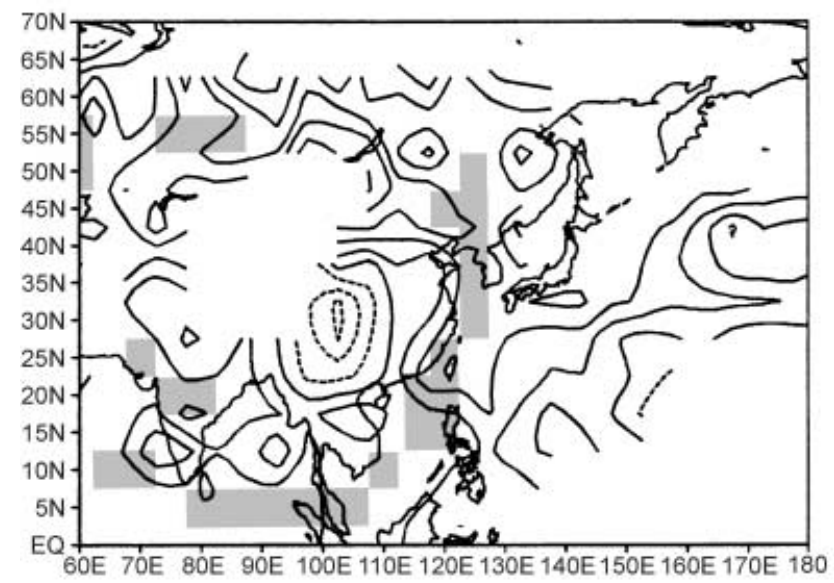

a

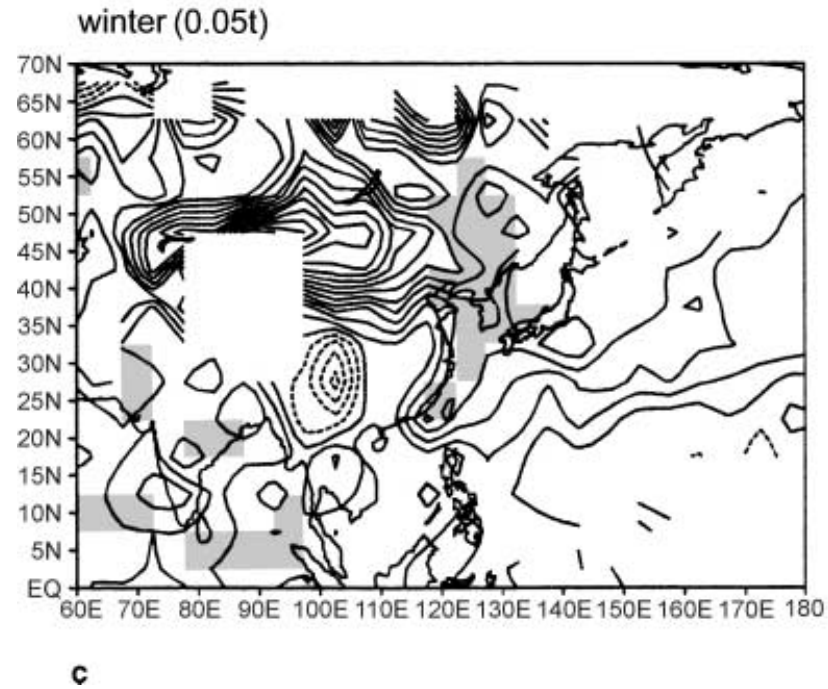

The temperature increase in Taiwan occurred most significantly during the warm season. As indicated in Table 1, the rate of increase in the summer temperature is higher than that for the winter temperature, resulting in an increase in the annual temperature range. At some stations (e.g., Taitung) the difference between the increases in summer and winter can be as large as $0.8^{\circ} \mathrm{C} / 100$ years. Overall, the stations in northwestern Taiwan exhibit smaller differences between the summer and winter warming rates. This result may seem to be at odds with the previous results (e.g., Jones et al., 1999; Hansen et al., 1999), which show that the hemispheric mean SAT in the winter exhibits a larger increasing trend during winter than in the summer. As indicated by Hansen et al. (1999), the summer $(0.05 \mathrm{t})$

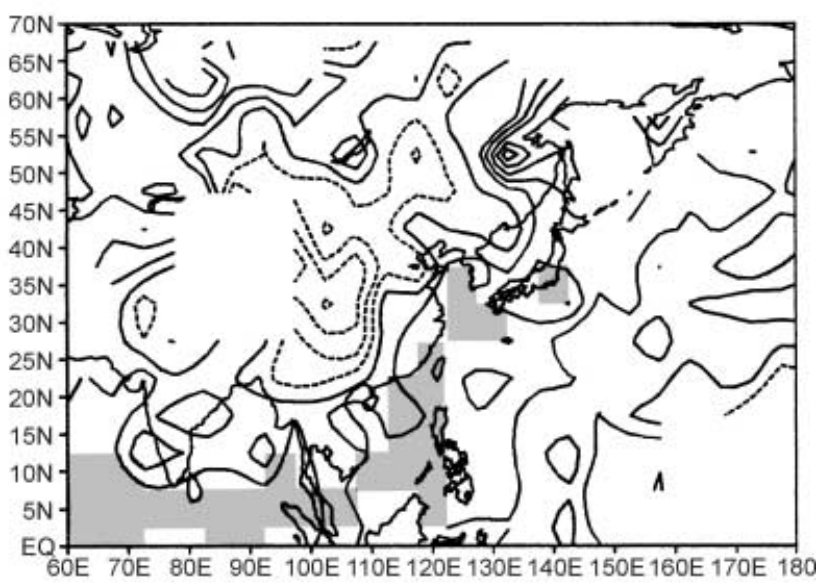

b

Fig. 3. Slopes of the linear trend in LSST. The contour interval is $0.5^{\circ} \mathrm{C} / 100$ year. Shading indicates the region where the slope is statistically significant at the 0.05 level

warming in the tropics occurs throughout the year, while the high latitude warming occurs mainly in the winter, especially in the Northern Hemisphere. Furthermore, the amplitude of warming in the high latitude is much larger in the winter than in the summer. The mean SAT trend in the Northern Hemisphere is therefore larger for the winter. The result shown here however indicates that the summertime warming rate can be larger in the low latitudes where the mechanisms are different from the dominant mechanisms (e.g., ice-albedo feedback) in the high latitudes.

The diurnal temperature range in Taiwan has been decreasing due to the larger warming trend in the nighttime temperature, as shown in Table 1. This result is consistent with the IPCC (1996) 
finding that the worldwide increases in the minimum temperature were about twice those in the maximum temperature. In Taiwan, the increase in the minimum temperature can be even larger. For example, it is about a 6-7 factor larger than the increase in the maximum temperature at Tainan and Taitung.

A climate change may lead to at least three types of changes: a change in the mean, a change in the variance, and a change in both (Meehl et al., 2000a, b). The frequency of extreme high and low temperatures can therefore change. The trend in the number of days when the daily-mean temperature exceeds $28^{\circ} \mathrm{C}$, which is the official temperature criterion for turning on air conditioning in public buildings, is shown in Table 1. The occurrence of warm weather has been increasing at three stations, namely, Taichung, Hengchun, and Taitung. The slopes of the linear trends are between 14 and 33 days/ 100 years.
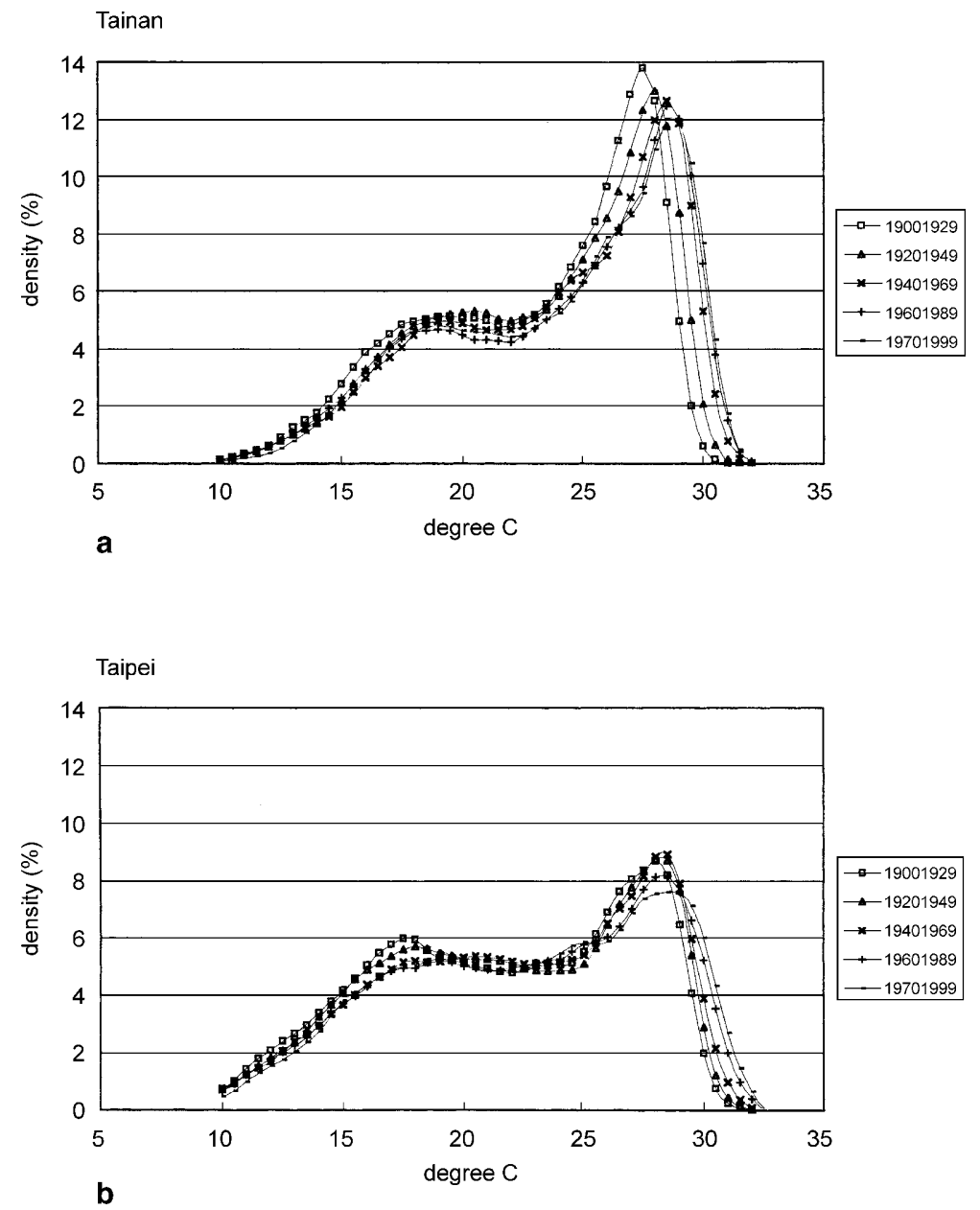

Taiwan is under the influence of the East Asian winter monsoon. When the cold surge occurs, the SAT can drop below $10^{\circ} \mathrm{C}$ in the winter. One of the official criterions in Taiwan for a cold surge occurrence is $13^{\circ} \mathrm{C}$. This criterion was adopted in this study to define a cold weather occurrence. Taipei, the northernmost station, is the only station exhibiting a significantly decreasing trend at a rate of 3.2 days/100 years. A significant linear trend did not appear in any of the other stations. Even in Taipei, the decreasing rate, although significant, is too small to result in serious impact.

The above results indicate that the temperature frequency distribution at some stations in Taiwan has gone through a significant change for the past 100 years. This can be clearly seen in the frequency distributions at Tainan and Taipei, shown in Fig. 4. In order to bring out the real structure, a Gaussian kernel estimator was used to a find a best-fit distribution (Tapia and Thompson, 1978). Various intervals were tested and $0.5^{\circ} \mathrm{C}$ was found
Fig. 4. The best-fit frequency distribution of the daily-mean temperature for the following periods: 1900-1929, 1920-1949, 1940-1969, 1960-1989, and 1970-1999 at a Tainan, and b Taipei. The frequency distributions are derived based on the Gaussian kernel estimator by setting interval equaling to $0.5^{\circ} \mathrm{C}$ 
to produce the best distribution that was highly reproducible when different intervals were used and yet provided enough details. A comparison of the distribution curves for various 30 -year periods was done to investigate the climate change in the temperature frequency distribution. The frequency distribution of the daily temperature in Taiwan does not resemble the normal distribution (Fig. 4). Instead, it tends to have a bimodal distribution shape and is negatively skewed with the mode biased toward higher temperatures. The long tail at the lower temperature end reflects the characteristics of Taiwan's climate, which can be viewed as a subtropical climate affected by a winter monsoon that brings cold surges in the winter. In both Taipei and Tainan, the high temperature end of the curve has been systematically shifting toward higher temperatures from the 1900-1929 period to the 1970-1999 period. The accumulated frequency for the temperature exceeding $30^{\circ} \mathrm{C}$ increased significantly from the 1900-1929 period to the 1960-1989 period. Although the curves at the lower temperature end also tended to shift gradually toward higher temperatures, these changes are not significant for all periods. The above results indicate that the increasing occurrence of warm weather has been an island-wide phenomenon in Taiwan, while the occurrence of cold weather has not changed significantly. This result also indicates that the temperature change in Taiwan belongs to a change of the third kind - change in both mean and variance.

One of the factors that is difficult to remove from the data is the heat island effect due to urbanization. There is no doubt that the heat island effect has contributed substantially to the temperature increase in Taiwan especially in the last few decades. However, a closer examination reveals that the heat island effect alone can not be responsible for the continuous temperature increase shown here. As shown in Fig. 4, the largest shift in the frequency distribution toward higher temperature occurred in the first half of the 20th century when extensive urbanization had not occurred in Taiwan. The impact of the heat island effect during this period is likely very small. Linear regression analysis was also applied to the SAT at stations that have shorter periods of observation. The result indicates that the temperature at most of these stations also exhibited an increasing trend between 19501999, although some of them did not pass the significant test because of the large interannual and decadal fluctuations. Stations that were much less influenced by the heat island effect, e.g., in the high mountains and at small isolated islands, also showed the same warming trends. Furthermore, although five out of the six stations chosen by this study exhibited increasing trends during 1950-1999, the rates of increase were much smaller than those in the past 100 years, except in Taipei. If the heat island effect had been the dominant factor in causing this trend, the rate of increase for the second half of the 20th century would have been larger than that for the first fifty years. The facts discussed above suggest that the increasing temperature trend observed in Taiwan was not caused by the heat island effect alone and is closely related to the global warming phenomenon.

Also shown in Table 1 are the trends for the annual-mean water vapor pressure at the six stations. Three of the six stations, namely, Taipei, Tainan, Taitung, exhibit significantly increasing trends, while the other three fail to pass the significant test. This increase in water vapor could be caused by an increase in either the moisture transport or the surface evaporation. The former may not be a positive factor because, as will be discussed later, the summer East Asian monsoon, which is the main circulation transporting moisture to Taiwan, seems to have been weakening in the past 100 years. An increase in surface evaporation is therefore more likely to be responsible for the increase in water vapor pressure in Taiwan, which in turn can enhance the greenhouse effect locally. As a result, the water vapor feedback could have partially led to an enhanced warming in Taiwan, as suggested by Manabe and Wetherald (1967). This water vapor feedback is expected to be more effective in the lower latitudes, such as Taiwan, than in the higher latitudes.

\subsection{Precipitation}

While there is an island-wide warming trend, the geographical distribution of long-term precipitation fluctuation in Taiwan is more complicated. As shown in Fig. 5 and Table 2, the linear trend model simulates the annual precipitation at four of the eight stations shown here. Three stations 


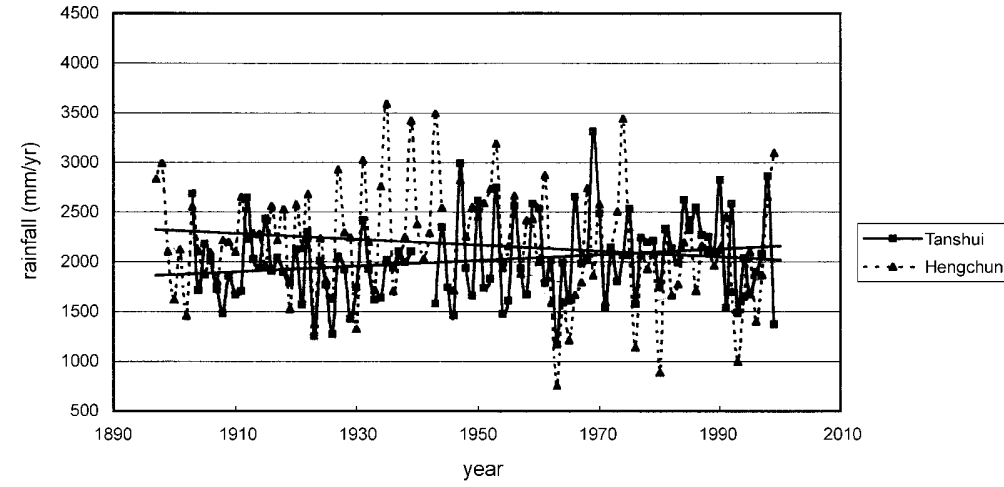

Fig. 5. Annual precipitation time series at Tanshui (northern Taiwan, solid curve) and Hengchun (southern Taiwan, dashed curve). Solid lines are the best-fit linear trends among the four are located in northeastern Taiwan and exhibit increasing trends with slopes between 3-4 mm/year. Hengchun, which exhibits a decreasing trend at a rate of $4 \mathrm{~mm} /$ year, is located in the southern tip of Taiwan. It is interesting to note that, although the trends at some of the other stations were not statistically significant, the positive trends generally appeared in northeastern Taiwan while the negative trends tended to appear in southwestern Taiwan. An examination of the seasonal precipitation indicates that the increasing precipitation in northeastern Taiwan occurred primarily in either spring (e.g., Hsinchu) or autumn (e.g., Tanshui, Hualien). These two seasons happen to be the rainy seasons at those stations. On the contrary, the decreasing precipitation at Hengchun (southern Taiwan) occurred mainly in the dry season (i.e., summer). These results indicate that northeastern Taiwan has become wetter during the wet season while southern Taiwan has become drier in the dry season. Such a long-term trend suggests an enhanced seasonal cycle of precipitation in Taiwan as a whole and increasing water stress in southern Taiwan.

Also shown in Table 2 is the annual number of precipitation day. A precipitation day is defined as a day when the daily precipitation exceeds $0.1 \mathrm{~mm} /$ day according to the definition by the Central Weather Bureau in Taiwan. Six of the eight stations exhibited a significant linear trend. The slopes of the linear trends vary dramatically between -0.36 and 0.57 day/year from station to station. This means that the number of precipitation days has decreased by more than one month at some stations while increasing by almost two months at Hsinchu since the beginning of the 20th century. Overall speaking, most of regions in Taiwan have been experiencing a significant decrease in the annual number of precipitation days. The reason for this coherent spatial structure is not understood at this stage. One may speculate that the weakening of the East Asian monsoon, as described below, may contribute to this phenomenon.

We have also examined the occurrence of a heavy precipitation event, which is defined as a day when the daily precipitation exceeds $50 \mathrm{~mm} /$ day. Only those stations in the northern (e.g., Tanshui and Taipei) and eastern (e.g., Hualien) Taiwan showed positive trends (Table 2). Although the linear trends at most of the stations were not statistically significant, it is interesting to note that these trends are positive in northern Taiwan and negative in southern Taiwan. The slopes of these trends are only about 0.03 day/ year and are too small to cause a serious impact.

\subsection{Circulation}

The weather and climate in Taiwan is strongly affected by fluctuations in the East Asian monsoon. It is therefore worthwhile exploring the long-term changes in the East Asian monsoon and its relationship with the local changes in Taiwan. Shown in Fig. 6 are the slopes of the linear trends in GMSLP at every grid point. The summertime sea-level pressure in eastern China and marine East Asia (e.g., Taiwan, Japan, and Korea) has increased systematically for the past 100 years, while the wintertime sea-level pressure has decreased systematically in eastern China and Siberia. The East Asian monsoon system over the Asian continent has been characterized by low-pressure and high-pressure systems during the summer and winter, respectively. Thus, a systematical increase and decrease in the sealevel pressure during the summer and winter, 
annual (0.05t)

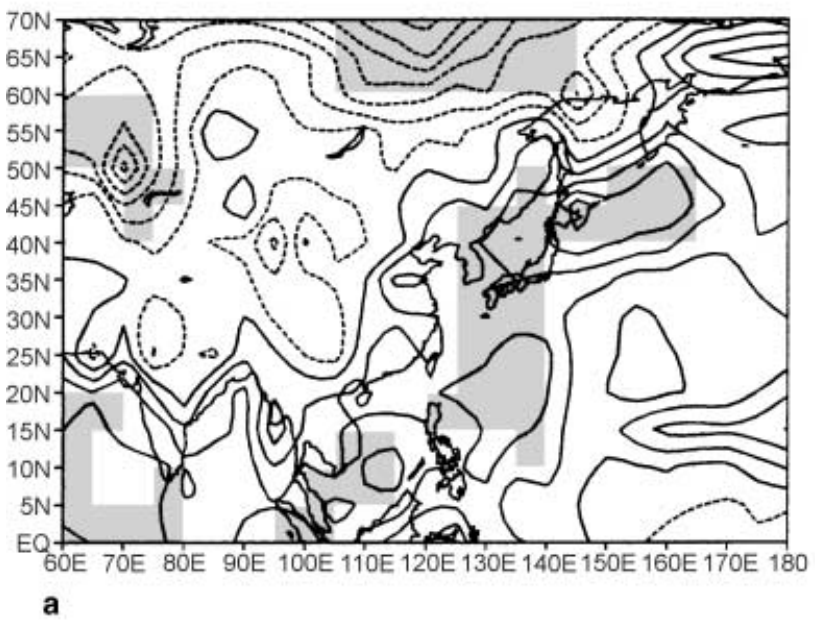

winter (0.05t)

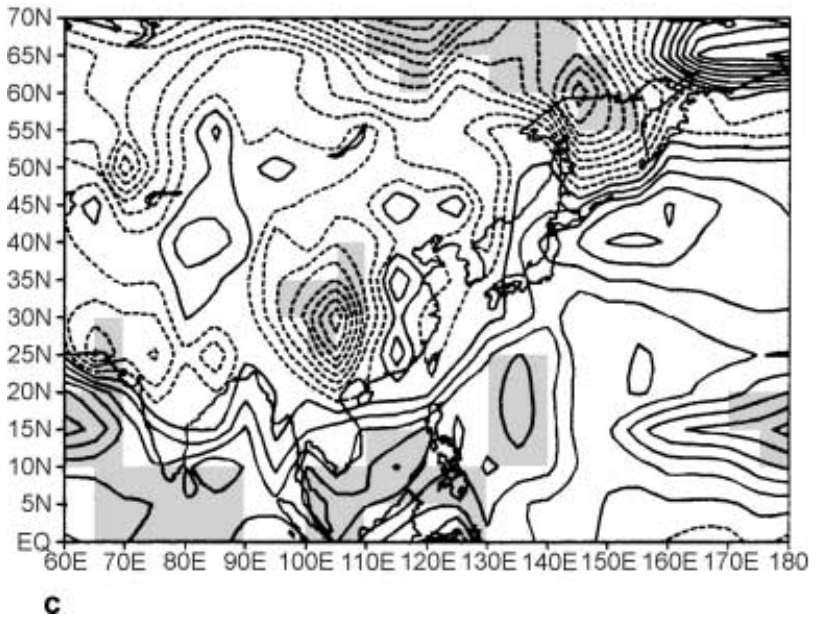

respectively, indicates a continuous weakening of the East Asian monsoon in the past century. The weakening of the East Asian monsoon is also evident in a study using the NCEP reanalysis over a much shorter period, e.g., 1949-1998 (not shown). The accompanied features are weakened northeasterly and southwesterly monsoons during the winter and summer, respectively.

\section{Projection of future climate}

This section investigates the future climate change based on a projection of the IPCC scenario simulation. Only the results of the greenhouse gas/aerosol simulation and their departures from the control simulation will be discussed here. Since the model resolutions are too coarse to resolve Taiwan, the discussion in this section will focus on the climate change in East Asia and the summer $(0.05 \mathrm{t})$

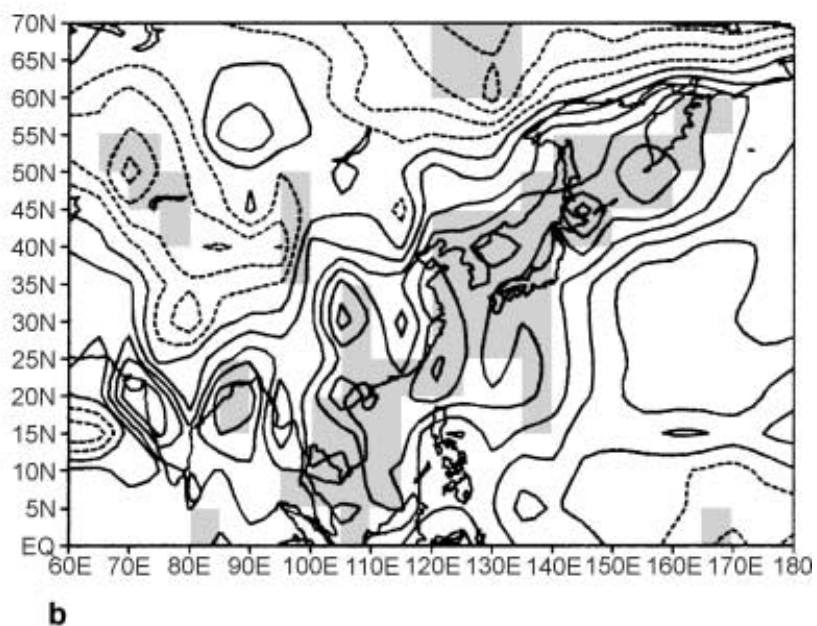

Fig. 6. Slopes of the linear trends in GMSLP. The contour interval is $50 \mathrm{hPa} / 100$ year. Shading indicates the region where the slope is statistically significant at the 0.05 level

change in the area-mean values for the region $\left(110^{\circ} \mathrm{E}-130^{\circ} \mathrm{E}, 15^{\circ} \mathrm{N}-30^{\circ} \mathrm{N}\right)$ to infer the possible climate change near Taiwan.

\subsection{Present climate simulation}

Before presenting the results of the future projection, it is important to understand the capability of each coupled model in simulating the present climate, which is defined as the 30-year means from 1961-1990. Figure 7 shows the observed SAT and the simulated SAT by five models. Both the NCEP reanalysis and the CRU surface temperature are also plotted in Fig. 7 for both comparison and evaluation. The similarity between the two observed fields is clearly evident. Most models are able to simulate the gross features of the observed field, e.g., the meridional 
(a) CRU

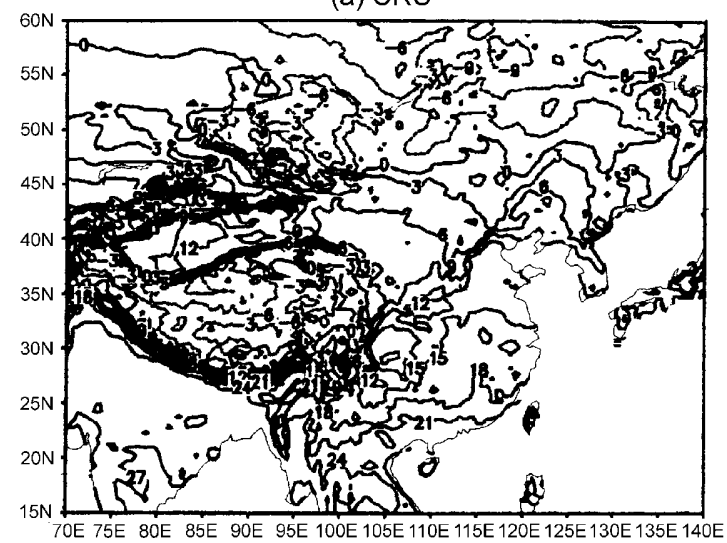

(c) CCCma

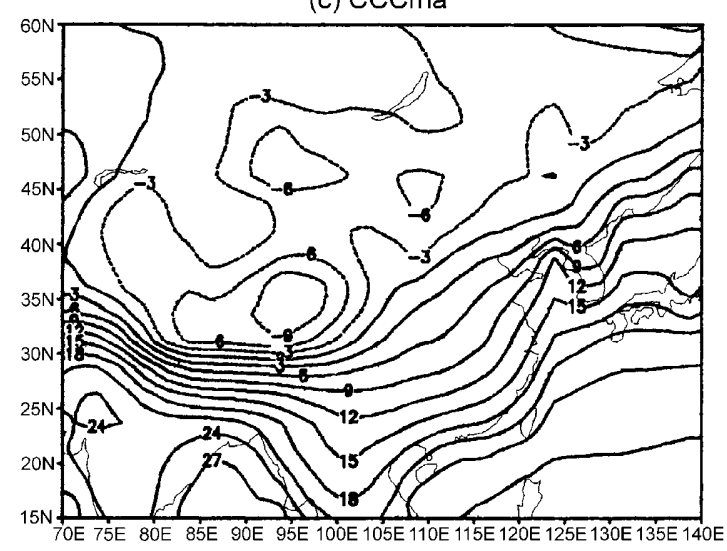

(e) CCSR/NIES

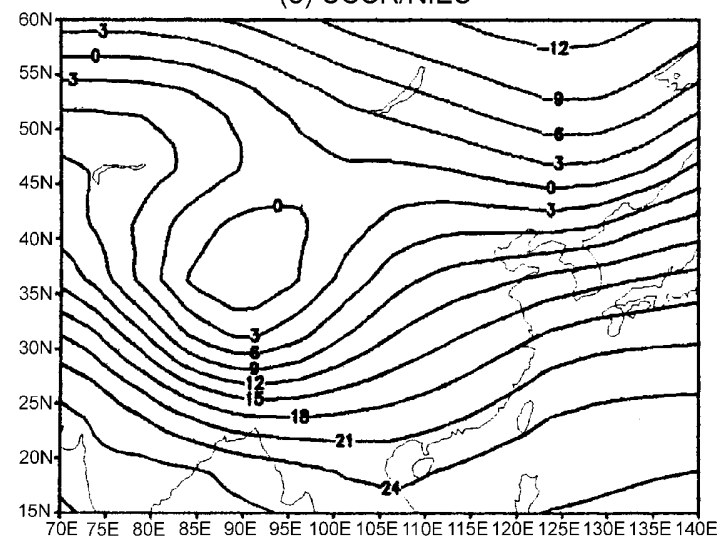

(g) $\mathrm{HadCM} 3$

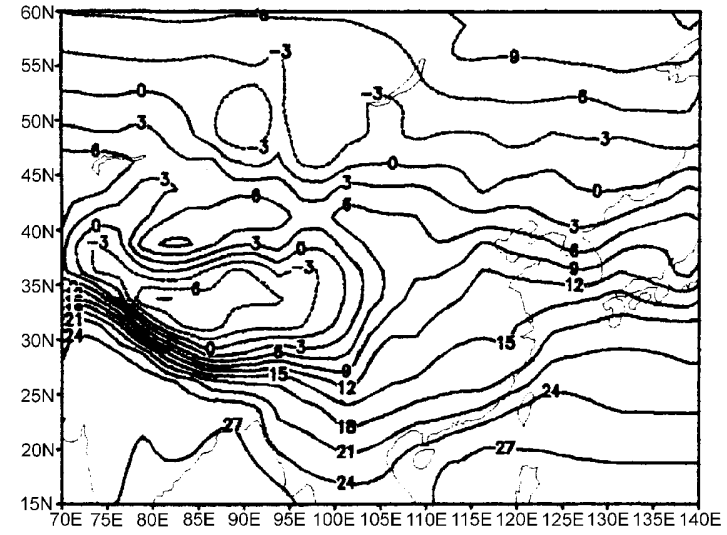

(b) NCEP

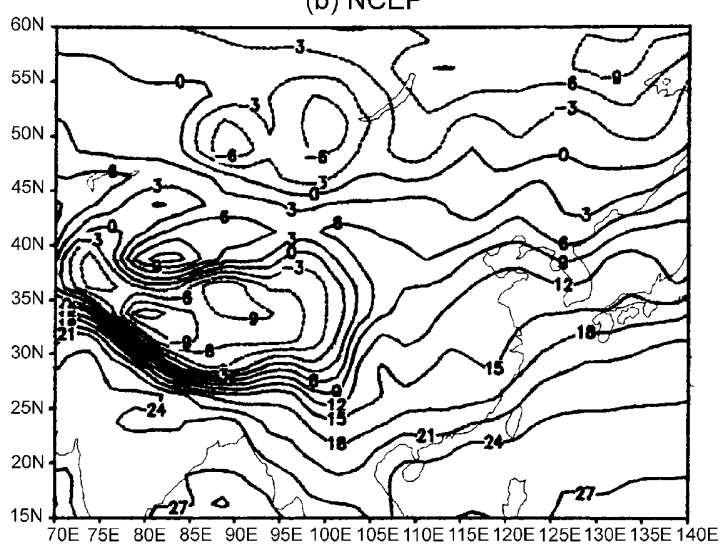

(d) CSIRO

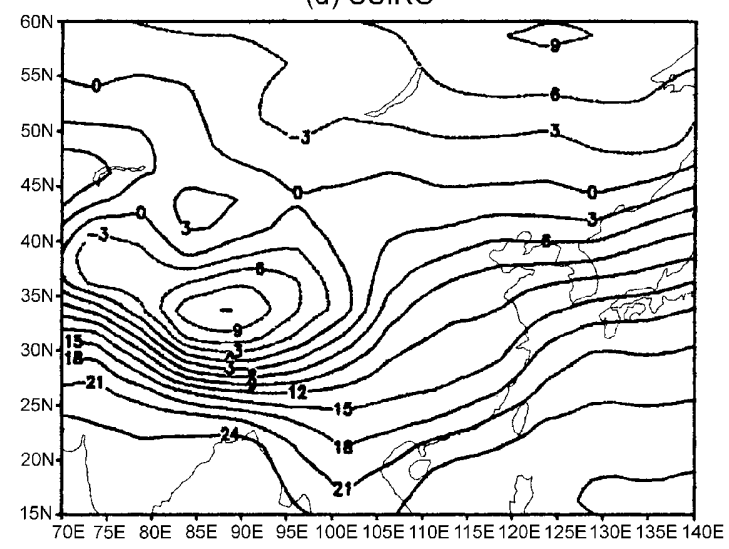

(f) $\mathrm{HadCM} 2$

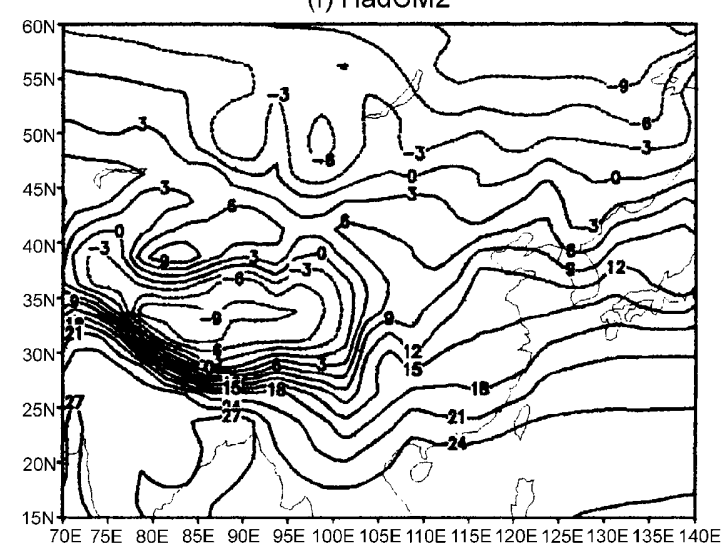

Fig. 7. Observed and simulated SAT for the 1961-1990 period: a CRU, b NCEP, c CCCma, d CSIRO, e CCSR, f HadCM2, and g HadCM3. The interval is $3^{\circ} \mathrm{C}$ 
gradient in East Asia and the low temperature over the Tibetan Plateau. However, each model has its own bias. The HadCM2 and HadCM3 both reproduce a wavy structure spanning across northern China, Korea and Japan. This feature was not successfully simulated by the other models, perhaps partly due to the coarse resolution. While the simulated SAT over Siberia was too low in the CCSR, HadCM2 and HadCM3, it was too high in the CCCma. Most of the models simulated reasonable temperatures in the western North Pacific and the South China Sea. The HadCM3 is an exception and simulated a temperature field that was too high. The low temperatures over the Tibetan Plateau were well simulated by the HadCM2 and HadCM3 models but was poorly simulated by the CCSR. It is quite clear that the HadCM2 reproduced many fine observed features that were missing in the simulations by the other models, e.g., the higher temperatures at the basins north of the Tibetan Plateau. The HadCM2 seems to have produced the best results among all of the models.

Figure 8 presents the observed and simulated precipitation. The CRU and GPCP precipitation data are also plotted to represent the observed climatology. The GPCP data set covers only the 1979-1999 period but provides precipitation data over both land and ocean. Although the CRU precipitation is available for a much longer period, only those over land are available. It is clear from Figure 8 that the observed precipitation based on these two data sets bears great similarity. The consistency between the two data sets yields greater confidence in the GPCP precipitation as its data over the ocean are used as the basis to validate the model precipitation.

The discrepancy between the precipitation simulated by different models is obviously much larger than that for temperature. The observed maximum precipitation can be found in the Bay of Bengal, the eastern Indian Ocean, the Philippine Sea, and the northeast-southwestward tilting band extending from the South China Sea to Japan. The regions of minimum precipitation are located in northwestern China and in the subtropical western North Pacific. The minimum and maximum precipitation in East Asia is aligned in such a manner to form the banded structure that significantly affects the East Asian climate. An adequate GCM should have the capability to simulate this banded structure to produce a reasonable climate simulation in East Asia. Although all models tend to produce the maximum precipitation somewhere in the Philippine Sea, the exact location is often incorrect. All models except the HadCM3 had difficulty simulating the minimum precipitation in the area influenced by the Pacific subtropical anticyclone. Another important feature affecting the East Asian Climate is the precipitation band extending from the South China Sea to the west of Japan. The precipitation band located to the north of the subtropical anticyclone is a convergence zone related to the stationary Mei-Yu front in the spring and the front-active region in the winter. The HadCM2 seemed to be the only model able to simulate this narrow feature.

The maximum precipitation in the Bay of Bengal occurs mostly in the summer. Most models tend to simulate maximum precipitation somewhere in the Bay of Bengal, although most of them are located far too south. The CCCma model, different from other models, fails to simulate this feature; instead, it produces the maximum precipitation over the land areas, e.g., in Burma and Thailand. The HadCM2 and HadCM3 are the only two models that are able to simulate the minimum precipitation in Northwestern China. The HadCM2 however produces an unrealistic precipitation band along the southern periphery of the Tibetan Plateau. The land-sea contrast seems to have an overwhelming effect on the HadCM3 for it simulates a sharp precipitation gradient along the Asian continental outline. Although every model has its own deficiency in simulating precipitation, the HadCM2 seemed to produce the best precipitation simulation among the five models.

The above results indicate that the HadCM2 reproduces most of the observed temperature and precipitation features on a regional scale. It is therefore possible that this model could be the most reliable model among the five models considered in this study to project future climate changes in East Asia.

\subsection{Future projection}

The mean temperature and precipitation for the targeted 30-year period, which centers on the year when the prescribed greenhouse gas concentration 
(a) $\mathrm{CRU}$

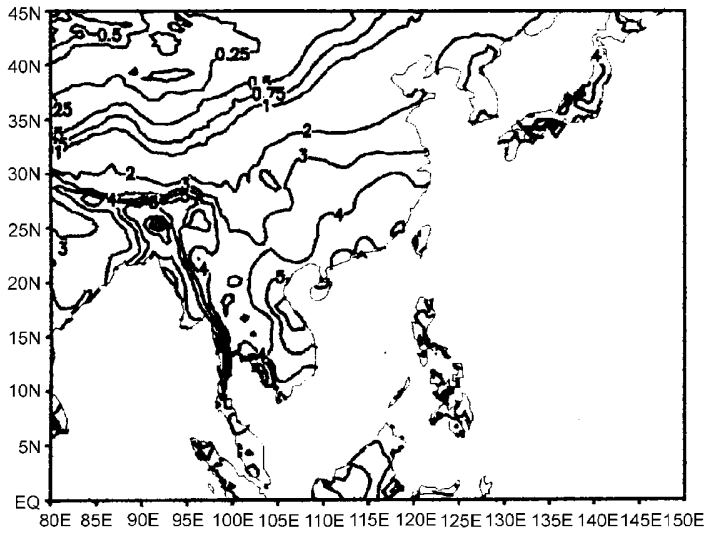

(c) $\mathrm{CCCma}$

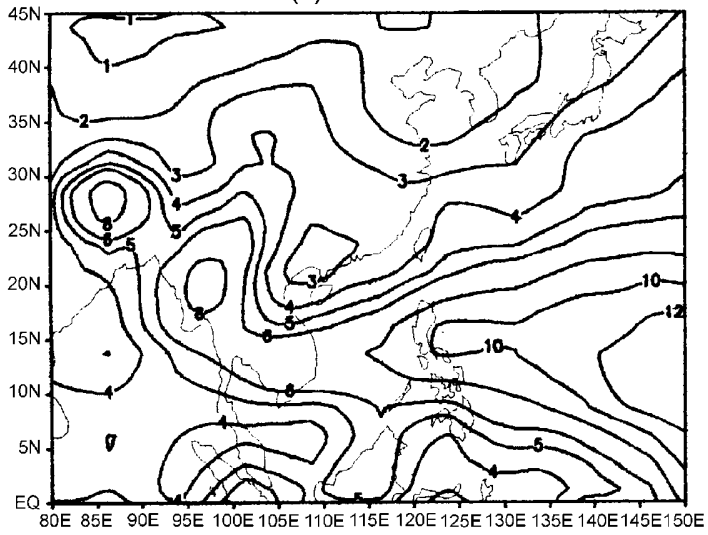

(e) CCSR / NIES

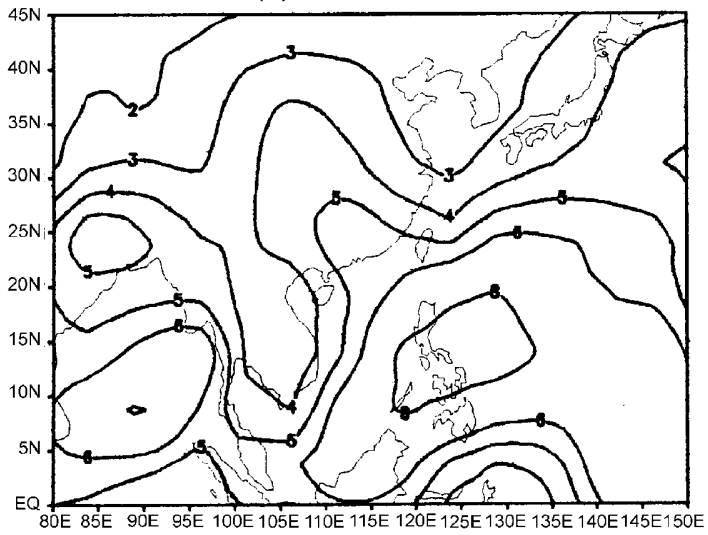

(g) $\mathrm{HadCM} 3$

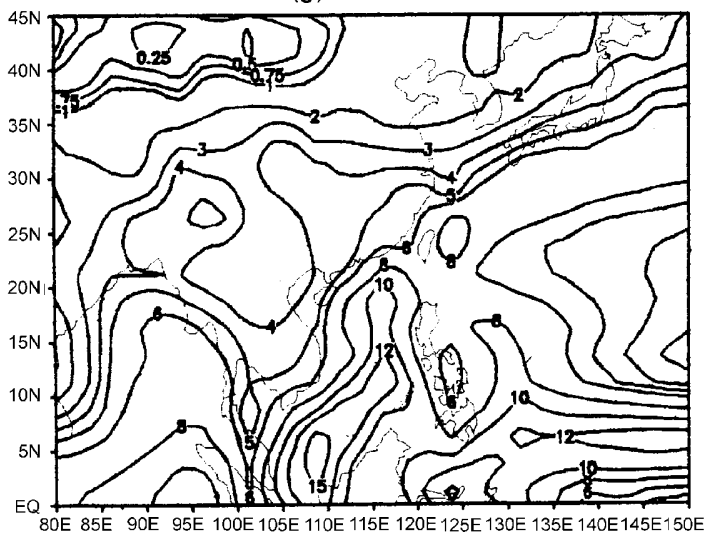

(b) GPCP (1979-1998)

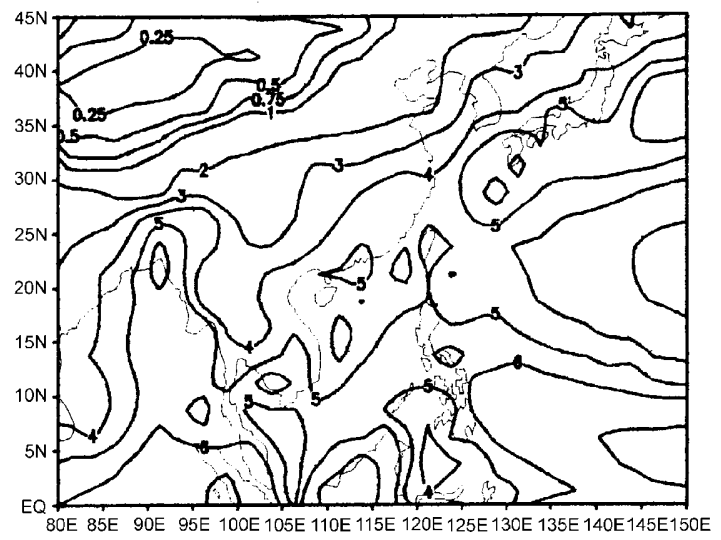

(d) CSIRO

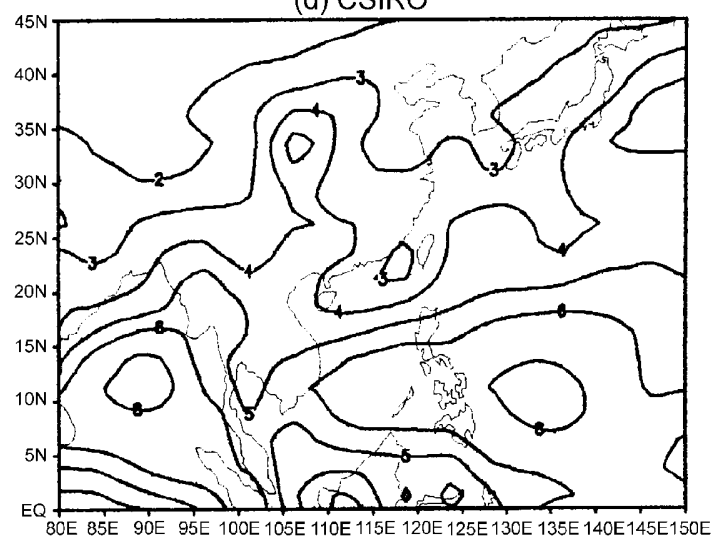

(f) $\mathrm{HadCM} 2$

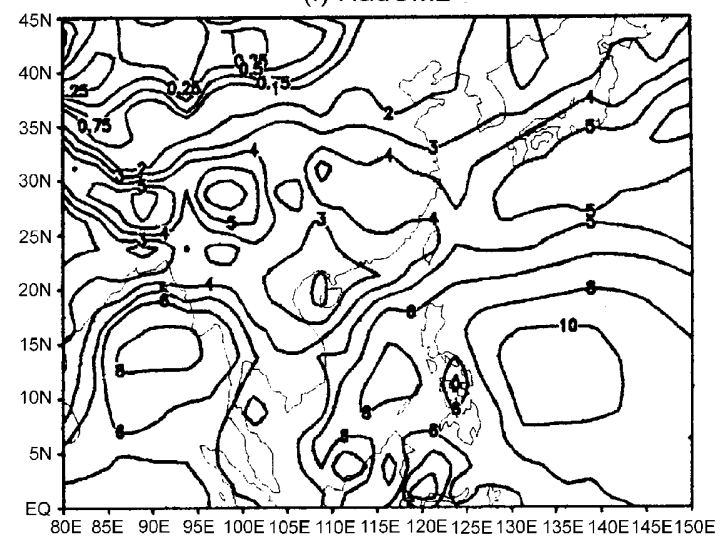

Fig. 8. Observed and simulated precipitation for the 1961-1990 period: a CRU, b GPCP (1979-1998), c CCCma, d CSIRO, e CCSR, f HadCM2, and $\mathbf{g} \mathrm{HadCM} 3$. The interval is $3 \mathrm{~mm} /$ day 
reaches 1.9 times the present value, were calculated to project the possible climate changes. Figure 9 presents the temperature changes be- tween the $1.9 \mathrm{CO}_{2}$ and $1 \mathrm{CO}_{2}$. The shading indicates the warming regions that are significant at the 0.05 level. It is clear that all models project (a) CCCma

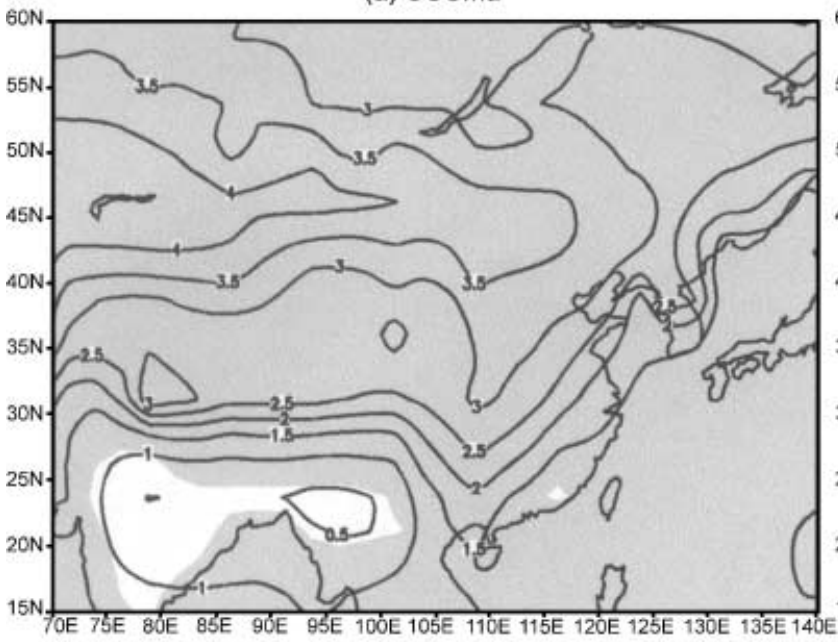

(c) CCSR / NIES

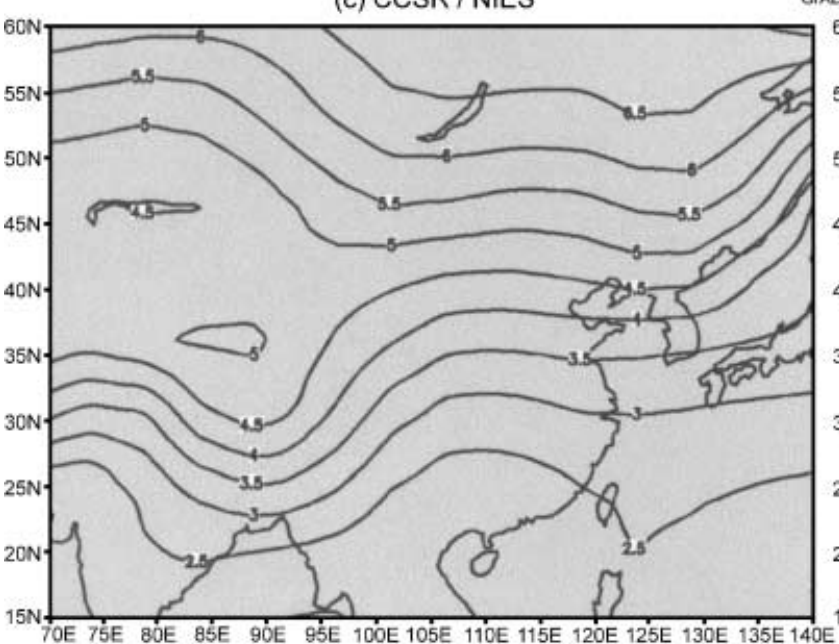

(e) $\mathrm{HadCM} 3$

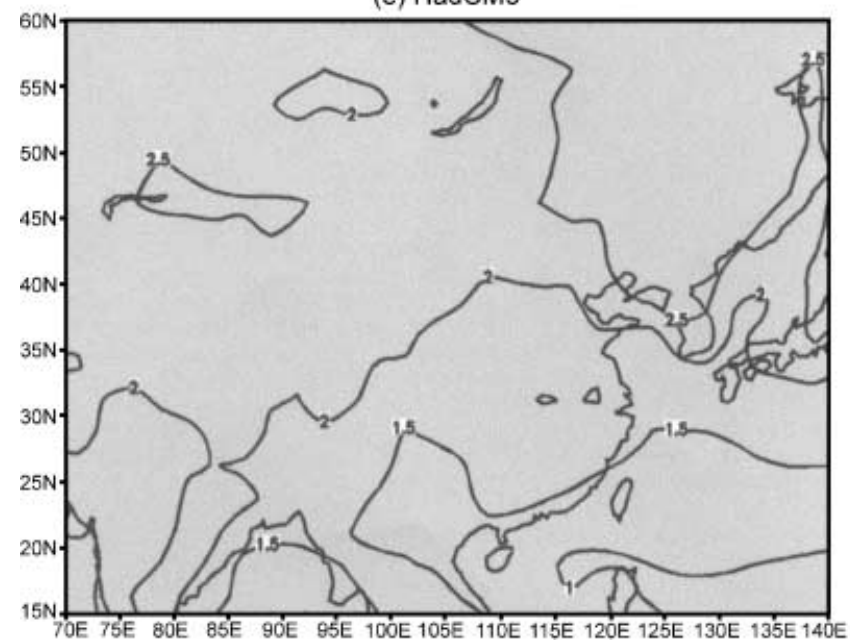

(b) CSIRO

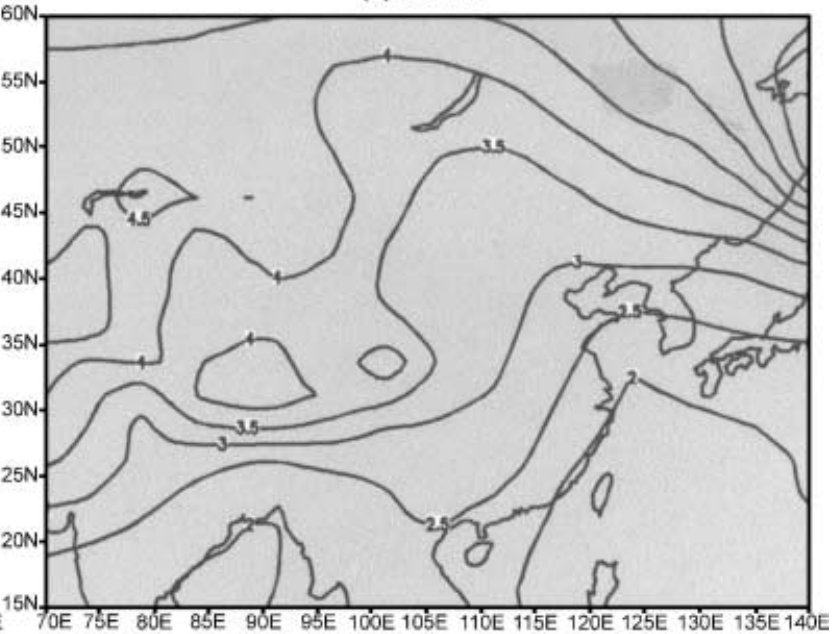

(d) $\mathrm{HadCM} 2$

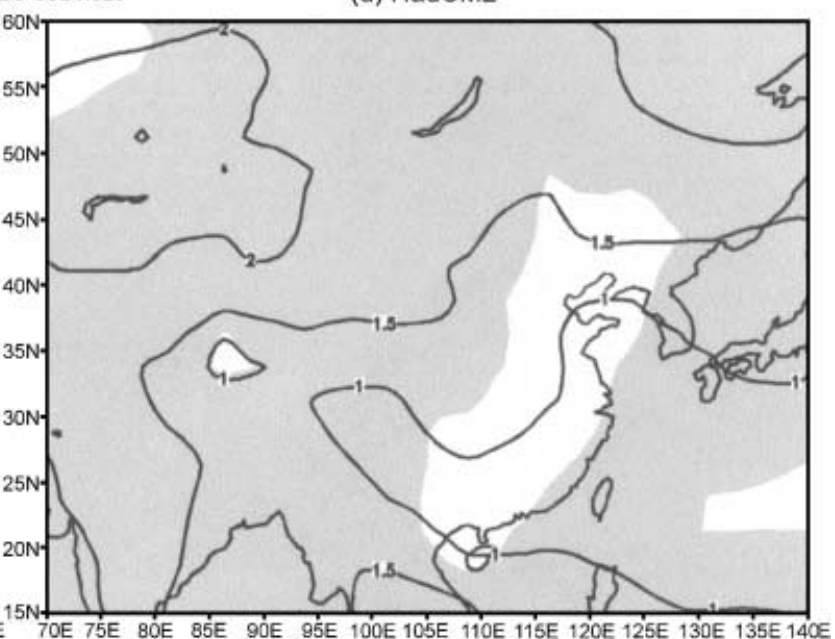

Fig. 9. Temperature changes between $1.9 \mathrm{CO}_{2}$ and $1 \mathrm{CO}_{2}$ $\left(1.9 \mathrm{CO}_{2}-1 \mathrm{CO}_{2}\right)$ in a CCCma, b CSIRO, c CCSR, d $\mathrm{HadCM} 2$, and e HadCM3. The contour interval is $0.5^{\circ} \mathrm{C}$ and the shading indicates the region where the change is statistically significant at the 0.05 level 
warming almost everywhere, except in East Asia for the HadCM2 and in South Asia for the CCCma. Several models project more warming in the higher latitudes than in the lower latitudes. This feature is most evident in the CCSR with the warming in Siberia exceeding $6.5^{\circ} \mathrm{C}$. Such a north-south contrast suggests a significantly reduced meridional temperature gradient and likely a weakened westerly. The CSIRO also projects a significantly reduced temperature gradient that is however located mostly in Northeast Asia. The large warming in the high latitudes projected by the CCSR and the CSIRO may be attributed to the strong ice-albedo feedback.

The largest temperature increase projected by the CCCma appears in northwestern Asia. An accompanying feature is the sharp temperature gradient in eastern China. Overall, there is more warming over the land than over the ocean in the CCCma projection, reflecting the effect of the land-sea contrast. In contrast to the above models, the warming projected by the HadCM2 and HadCM3 is generally smaller than $2{ }^{\circ} \mathrm{C}$ and is relatively geographically uniform. Unlike the other models, the land-sea contrast and the icealbedo feedback do not seem to have a dominant effect in the HadCM2 and HadCM3 projection.

Although the projections of these five models yield different temperature change patterns, they all project a warming trend in the future. The estimated area-mean temperature increases in the region $\left(110^{\circ} \mathrm{E}-130^{\circ} \mathrm{E}, 15^{\circ} \mathrm{N}-30^{\circ} \mathrm{N}\right)$ near Taiwan (Fig. 10a, b) range from $0.9^{\circ} \mathrm{C}$ in the $\mathrm{HadCM} 2$ to $2.4^{\circ} \mathrm{C}$ in the CCSR. The standard deviations in the area-mean temperature near Taiwan for the control runs of the CCCma, CCSR, CSIRO, HadCM2, and HadCM3 are $0.27^{\circ} \mathrm{C}$, $0.28^{\circ} \mathrm{C}, 0.30^{\circ} \mathrm{C}$, and $0.33{ }^{\circ} \mathrm{C}$, and $0.27^{\circ} \mathrm{C}$, respectively. Since the greenhouse gas and aerosol concentrations in the control runs were fixed at the pre-industrial level, the variability in these runs can be viewed as the "natural variability" in the respective models. The projected temperature increases by all five models are at least three times

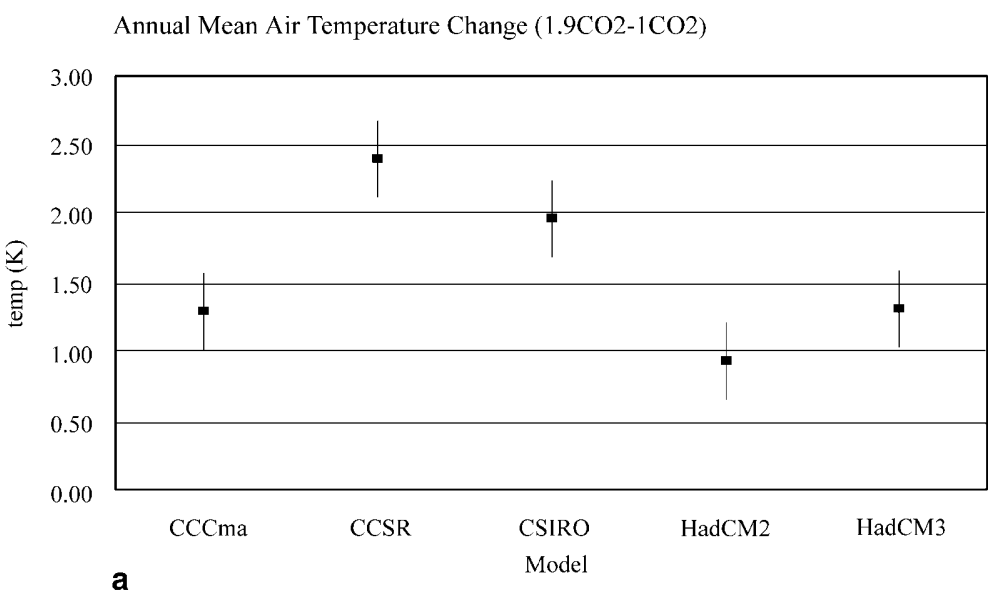

Annual Mean Precipitation Change

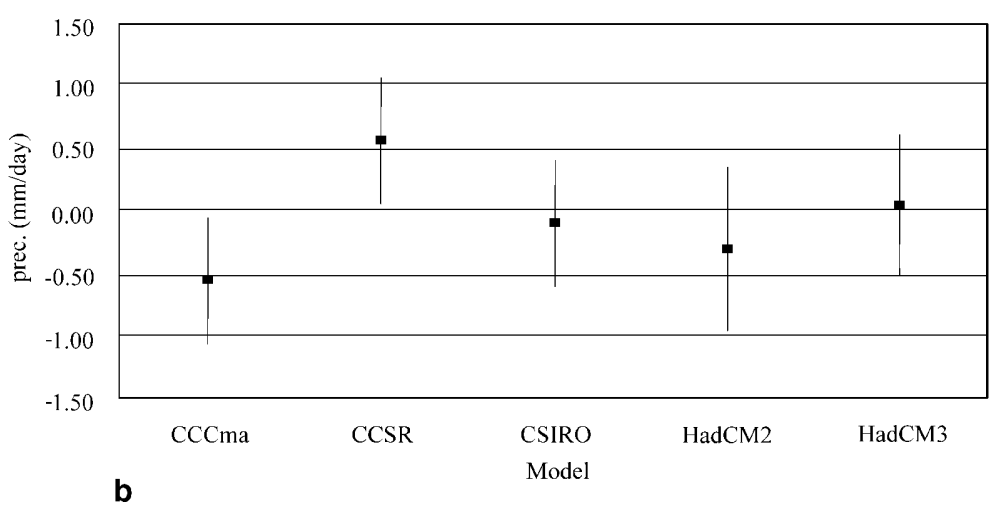

Fig. 10. Area-averaged annual-mean a SAT, and $\mathbf{b}$ precipitation changes between $1.9 \mathrm{CO}_{2}$ and $1 \mathrm{CO}_{2}\left(1.9 \mathrm{CO}_{2}-1 \mathrm{CO}_{2}\right)$ in the area $\left(110^{\circ} \mathrm{E}-\right.$ $\left.130^{\circ} \mathrm{E}, 15^{\circ} \mathrm{N}-30^{\circ} \mathrm{N}\right)$ near Taiwan for the five models. The error bar indicates the standard deviation of the control run, which represents the natural variability of each model 
the respective standard deviations, which represent a large signal-to-noise ratio. It follows that the projected temperature increases by these models are indeed forced by the radiative forcing due to the increased greenhouse gas and aerosol concentrations.

The projected precipitation changes shown in Fig. 11 are much more complicated and show little (a) CCCma

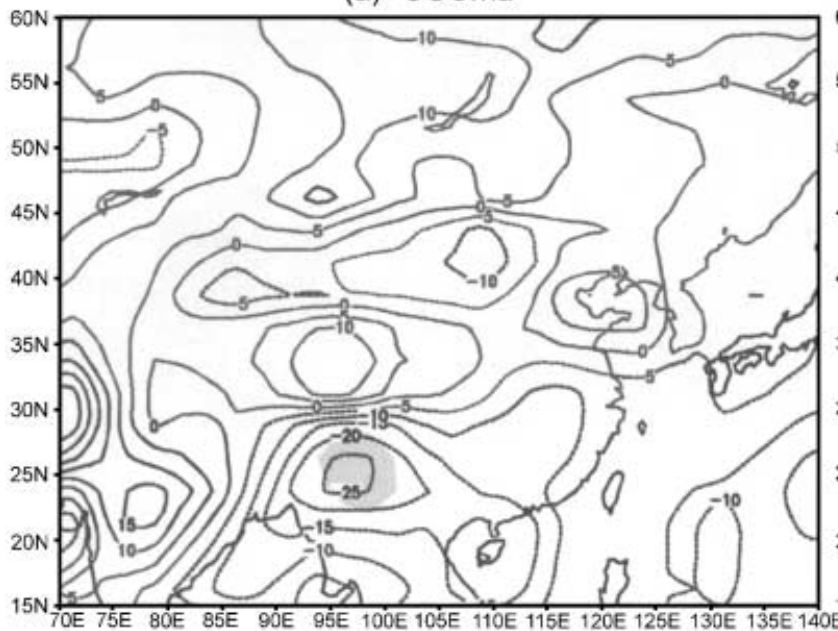

(b) CSIRO

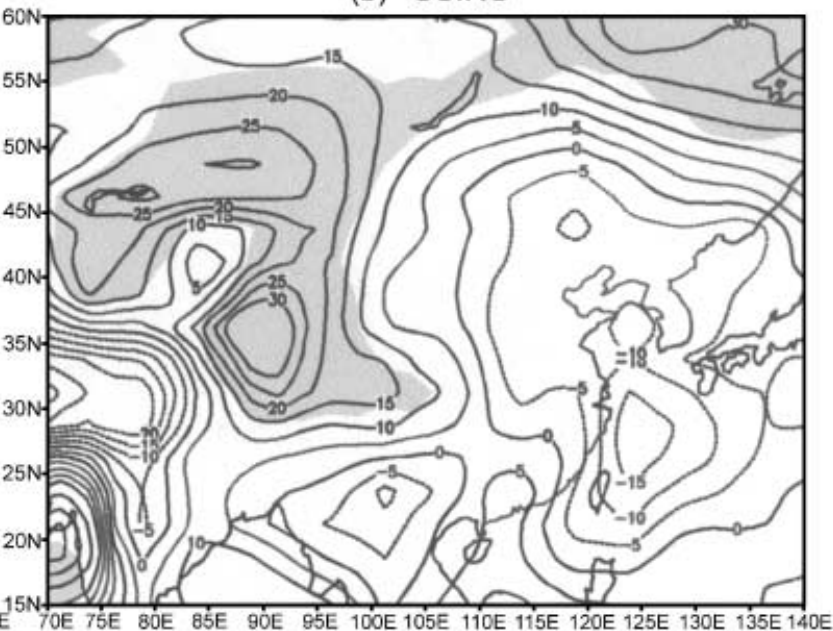

(c) CCSR/NIES

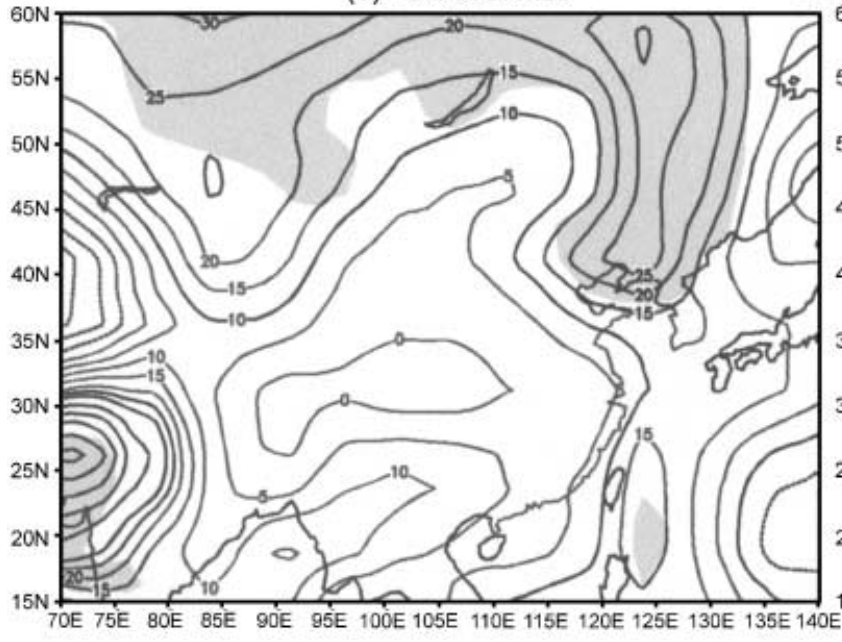

(e) $\mathrm{HadCM} 3$

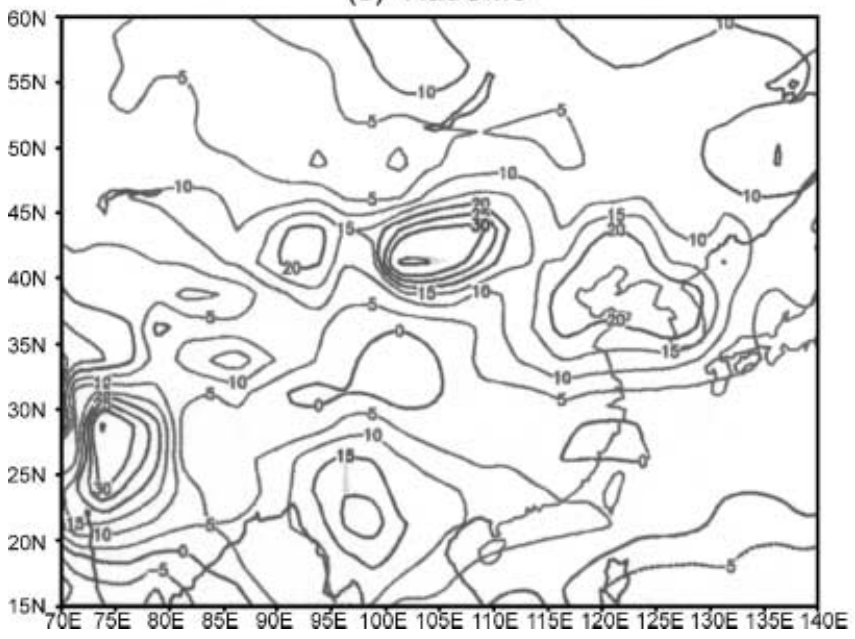

GrADS: COLAMIGES

(d) HadCM2

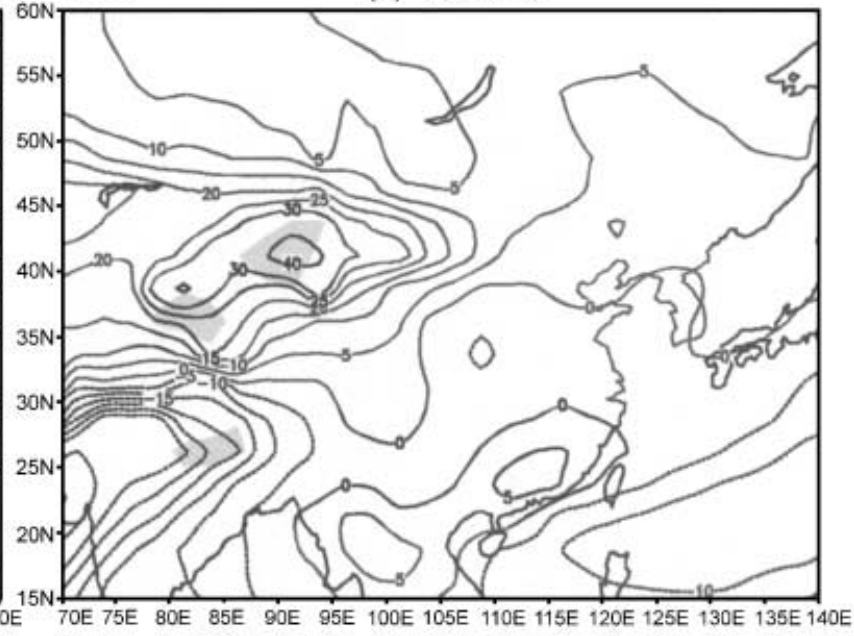

Fig. 11. Precipitation changes between $1.9 \mathrm{CO}_{2}$ and $1 \mathrm{CO}_{2}$ $\left(1.9 \mathrm{CO}_{2}-1 \mathrm{CO}_{2}\right)$ in a CCCma, b CSIRO, c CCSR, d $\mathrm{HadCM} 2$, and e HadCM3. The figure is presented in terms of the percentage relative to the mean values in $1 \mathrm{CO}_{2}$. The contour interval is 5 percent and the shading indicates the region where the change is statistically significant at the 0.05 level 
consistency between the models. The changes are plotted in terms of the percentage of simulated present-climate precipitation and are shaded if significant at the 0.05 level. The CSIRO and CCSR are the only two models that projected statistically significant precipitation changes in limited areas. Although different in detail, all models projected precipitation increases in the higher latitudes, which is particularly significant in the CSIRO and CCSR. No model projected significant precipitation changes in East Asia.

As shown in Fig. 10b, the area-mean precipitation change near Taiwan ranges from about $-0.5 \mathrm{~mm} /$ day (CCCma) to about $0.6 \mathrm{~mm} /$ day (CCSR). However, these changes are not significantly large compared to the standard deviations of the control runs, which were $0.5,0.43,0.42$, 0.65 , and $0.56 \mathrm{~mm} /$ day for the CCSR, CSIRO, CCCma, HadCM2, and HadCM3, respectively. The results shown in Fig. 10b imply a low signalto-noise ratio and clearly indicate that these precipitation changes are within the range of natural variability for each model.

\section{Conclusions and discussions}

This study examined the secular climate change characteristics in Taiwan over the past 100 years and the relationship with the global climate change. Estimates for the likelihood of future climate changes in Taiwan were made based on the projection from the IPCC climate models.

In the past 100 years, Taiwan experienced an island-wide warming trend. The warming rate is between $1.0-1.4{ }^{\circ} \mathrm{C} / 100$ years. The warming rate for the summer temperature is higher than that for the winter temperature, leading to an increase in the annual temperature range. The daily temperature range has been on an increase due to the larger warming trend of the nighttime temperature. The warming in Taiwan is not an isolated feature; instead, it is closely connected to a large-scale circulation and SAT fluctuations. These related phenomena include the weakening of the East Asian monsoon, the warming of Northern Asia and marine East Asia, and the "warm land cool ocean" phenomenon.

The water vapor pressure has also increased significantly and could have enhanced the greenhouse effect. It is speculated that the increase in water vapor was due to an increase in the surface evaporation instead of increased moisture convergence. This is because the East Asian monsoon appeared to have been weakened during this period. The water vapor feedback may have resulted in a larger temperature increase in summer. This feedback process will tend to work more efficiently in the lower latitudes where the moisture is abundant. This can probably explain why the warming rate in Taiwan is much greater in the summer than in the winter.

An examination of the probability distribution of the daily-mean temperature for consecutive 30 -year periods starting from the beginning to the end of the 20th century indicates the increasing probability for the occurrence of high temperatures. This shift of probability toward high temperatures occurred most significantly in the first half of the century and is unlikely to be the result of the urban heat island effect. The increased rate of occurrence for extreme low temperatures was also observed in northern Taiwan but is less significant. This result suggests that both the mean and variance in the SAT in Taiwan have changed significantly since the beginning of the 20th century.

Although, as a whole, the precipitation in Taiwan has shown a tendency to increase in Northern Taiwan and to decrease in Southern Taiwan in the past 100 years, it exhibits a more complicated spatial pattern. The changes occur mainly in either the dry or rainy season and result in an enhanced seasonal cycle. The number of heavy precipitation days has been increasing at isolated stations. However, this phenomenon has not been a major problem affecting Taiwan's climate because of the small rate of increase.

The above changes in temperature and precipitation are consistent with the changes in large-scale circulation. The East Asian monsoon is found to have been weakening for the past 100 years. The weakening northeasterly monsoon can partially explain the rising winter temperature in Taiwan. The weakening southwesterly monsoon reflects the lesser influence of the monsoon trough and the greater dominance of the Pacific subtropical anticyclone that is always associated with a warmer, more stable and stagnant air mass. This change in circulation is consistent with the island-wide increase in the summer temperature and the decreasing summer precipitation in southern Taiwan. This result suggests 
that although the increase in the greenhouse gas concentration may contribute to the warming in Taiwan, the circulation changes also have a similar effect. Whether the enhanced greenhouse effect caused the circulation change and how they interacted are interesting and important questions, but beyond the scope of this study.

Among the five coupled GCM, the HadCM2 reproduced the most realistic temperature and precipitation distributions for East Asia in the present-climate simulation by taking into account the increasing concentration of both greenhouse gases and aerosols. Under consideration of both the warming effect from greenhouse gases and the cooling effect from aerosols, all projections from climate models indicated a warmer climate near Taiwan. The projected increase in the area-mean temperature near Taiwan ranged from $0.9-2.7^{\circ} \mathrm{C}$ relative to the 1961-1990 averaged temperature, when the $\mathrm{CO}_{2}$ concentration increased to 1.9 times the 1961-1990 level. These simulated temperature increases were statistically significant and can be attributed to the radiative forcing associated with the increased concentration of greenhouse gases and aerosols. The results from the CCCma and HadCM2 were derived based on an ensemble of three and four simulations, respectively. All members of the ensemble for the two models produced almost identical results. The fact that the results were not affected by the different initial conditions suggests that the radiative forcing from the added greenhouse gas and aerosol overwhelmed the nonlinear effect and had a dominant effect on the temperature increase.

Although all models projected significant warming, the pattern can be quite different. The changes in the East Asian monsoon can therefore be very different. In view of how the change in the monsoon system can affect the temperature near Taiwan, although all models projected warming in East Asia, the actual mechanism causing the changes may not be similar between the models.

The projected changes in precipitation were within the range of natural variability for all five models. The increased radiative forcing did not seem to induce precipitation changes that overwhelmed the natural variability. Therefore, one should conclude that there is no evidence supporting the possibility of precipitation changes near Taiwan based on the simulations from these five models.
Taiwan is a small island country. Its climate is affected not only by the regional land-sea contrast and the complex terrain, but also by the largescale East Asian monsoon system. It has been difficult to relate the local climate variation in Taiwan to the large-scale climatic fluctuation even in the present climate regime. To project future climate change in Taiwan is even a more difficult task and cannot be achieved based solely on the IPCC climate simulation. This study has in some sense pushed the IPCC results to the limit to explore its usefulness in simulating and projecting the East Asian monsoon. Such a practice has been done by several recent studies (e.g., Kitoh et al., 1997; Hu et al., 2000, and Meehl et al., 2000c) and has yielded useful information. However, one would need a regional climate model to downscale to a scale as small as Taiwan, which could be an even bigger challenge.

\section{Acknowledgments}

We thank Joyce Bian, Chi-How Chu, and Mei-Ching Chen for their assistance in calculation and figure preparation. This work was supported by the National Science Council, ROC, under Grant NSC 88-2621-Z-002-020 and NSC 892621-Z-002-014.

\section{References}

Allan R, Lindesay J, Parker D (1996) El Niño southern oscillation and climatic variability. CSIRO Publishing, Australia, $405 \mathrm{pp}$

Cane MA, Clement AC, Kaplan A, Kushnir Y, Pozdnyakov D, Seager R, Zebiak SE, Murtugudde R (1997) Twentiethcentury sea-surface temperature trends. Science 275: 957-960

Hansen J, Ruedy R, Glascoe J, Sato M (1999) GISS analysis of surface temperature change. J Geophys Res 104: 30, 997-31, 022

$\mathrm{Hu}$ Z-Z, Bengtsson L, Arpe K (2000) Impact of global warming on the Asian winter monsoon in a coupled GCM. J Geophys Res 105: 4607-4624

Huffman GJ, Adler RF, Arkin PA, Chang A, Ferraro R, Gruber A, Janowiak J, McNab A, Rudolf B, Schneider U (1997) The Global Precipitation Climatology Project (GPCP) combined precipitation dataset. Bull Amer Soc 78: $5-20$

Intergovernmental Panel on Climate Change (IPCC) (1996) Climate Change 1995. Edited by Houghton JT, Meira Filho LG, Callandar BA, Harris N, Kattenberg A, Maskell K. New York: Cambridge University Press, 572 pp

Jones PD (1994) Hemispheric surface air temperature variations: A reanalysis and an updated to 1993. J Climate 7: 1794-1802 
Jones PD, New MG, Parker DE, Marun S, Rigor IG (1999) Surface air temperature and its changes over the past 150 years. Rev Geophys 37: 173-199

Kalnay E, Kanamitsu M, Kistler R, Collins W, Deaven D, Gandin L, Iredell M, Saha S, White G, Woollen J, Zhu Y, Leetmaa A, Reynolds R, Chelliah M, Ebisuzaki W, Higgins W, Janowiak J, Mo KC, Ropelewski C, Wang J, Jenne R, Joseph D (1996) The NCEP/NCAR 40-year reanalysis project. Bull Amer Meteor Soc 77: 437-472

Kitoh A, Yukimoto S, Noda A, Motoi T (1997) Simulated changes in the Asian summer monsoon at times of increased atmospheric $\mathrm{CO}_{2}$. J Meteor Soc Japan 75: 1019-1031

Manabe S, Wetherald RT (1967) Thermal equilibrium of the atmosphere with a given distribution of relative humidity. J Atmos Sci 24: 241-259

Meehl GA, Karl T, Easterling DR, Changnon S, Pielke Jr. R, Changnon D, Evans J, Groisman PY, Knuston TR, Kunkel KE, Mearns LO, Parmesan C, Pulwarty R, Root T, Sylves RT, Whetton P, Zwiers F (2000c) An introduction to trends in extreme weather and climate events: Observations, socioeconomic, impacts, terrestrial ecological impacts, and model projections. Bull Amer Meteor Soc 81: 413-416

Meehl GA, Zwiers F, Evans J, Knutson T, Mearns L, Whetton P (2000b) Trends in extreme weather and climate events: Issues related to modeling extremes in projections of future climate change. Bull Amer Meteor Soc 81: 427-436
Meehl GA, Washington WM, Arblaster JM, Bettge TW, Strand Jr. WG (2000c) Anthropogenic forcing and decadal climate variability in sensitivity experiments of twentieth- and twenty-first-century climate. J Climate 13: 3728-3744

New MG, Hulme M, Jones PD (1999) Representing twentieth-century space-time variability. Part I: Development of a 1961-90 mean monthly terrestrial climatology. J Climate 12: 829-856

New MG, Hulme M, Jones PD (2000) Representing twentieth-century space-time variability. Part II: Development of 1901-1996 monthly grids of terrestrial surface climate. J Climate 13: 2217-2238

Parker DE, Folland CK, Jackson M (1995) Marine surface temperature: Observed variations and data requirements. Climatic Change 31: 559-600

Tapia RA, Thompson JR (1978) Nonparametric Probability Density Estimation. Baltimore: The Johns Hopkins University Press, $177 \mathrm{pp}$

Wallace JM, Zhang Y, Bajuk L (1996) Interpretation of interdecadal trends in Northern Hemisphere surface air temperature. J Climate 9: 249-259

Authors' addresses: Dr. H.-H. Hsu, Department of Atmospheric Sciences, National Taiwan University, Taipei, Taiwan (E-mail: hsu@atmos1.as.ntu.edu.tw); C.-T. Chen, Department of Earth Sciences, National Taiwan Normal University, Taipei, Taiwan 